\title{
SUS: análises, reflexões e contribuições
}

I Kenneth Rochel de Camargo Jr. |

Do estabelecimento de um conjunto de direitos e princípios na nova Carta Constitucional brasileira à implantação de fato das organizaçôes e dispositivos necessários à plena implementação desse conjunto, estende-se um longo, possivelmente interminável, processo. Esse é o processo de construção do SUS, que enfrentou (e enfrenta) numerosos obstáculos em sua história. Certamente há muito o que fazer para superá-los e termos finalmente um sistema de saúde à altura do que desejamos e merecemos como povo.

Não por acaso, a pesquisa sobre diversos aspectos ligados à estruturação e funcionamento do SUS é um dos principais pilares da Saúde Coletiva brasileira. Pelo viés da produção de conhecimento, esta é uma importante contribuição do nosso campo ao fortalecimento e expansão do SUS. E isto, evidentemente, se reflete na oferta de artigos que chegam às revistas da área, incluindo a Physis.

Embora tenhamos optado por não estabelecer temas a priori nas duas últimas ediçôes deste ano, percebemos, ao considerar o conjunto de artigos aprovados para esta edição, que um tema ad hoc praticamente se impunha.

Boa parte dos artigos deste número trata de aspectos fundamentais do SUS, trazendo análises críticas inovadoras que fornecem importantes subsídios para seu processo de gestão. Sendo assim, erigimos como tema deste número "SUS: análises, reflexões e contribuições", incluindo nove artigos, divididos em três blocos.

Um primeiro bloco é constituído por três artigos que abordam diversos aspectos relacionados à Estratégia de Saúde da Família (ESF). Este bloco é aberto por Sundfeld, que discute a questão da clínica ampliada no âmbito a ESF, tendo como disparador as demandas dirigidas a uma psicóloga integrante de um NASF. Seguem-se Trad e Espiridião, que apresentam os resultados de um estudo em municípios de porte variado em três estados do Nordeste, com ênfase 
nos sentidos atribuídos pelos usuários à noção de "humanização em saúde" e sua avaliação sobre diversos aspectos da ESF. Ferreira Neto e Kind trazem os dados de pesquisa sobre a adoção de técnicas grupais no âmbito da ESF, do ponto de vista de sua contribuição à promoção da saúde.

$\mathrm{O}$ segundo bloco tem dois artigos que tratam dos agentes comunitários de saúde (ACS), importantes atores na ESF. Santos, Pierantoni e Silva apresentam o perfil dos ACS, mostrando, a partir de uma perspectiva histórica, o trajeto de constituição desse novo personagem e o aspecto estratégico e sua contribuição para as açôes de saúde. Cotta et al., por sua vez, complementam a análise do papel estratégico do ACS com base em revisão de literatura sobre o tema.

O terceiro e último bloco do tema traz quatro artigos que abordam, de formas variáveis e com criatividade metodológica, a relação dos usuários com a gestão do SUS. Silva, Ferreira e Silva descrevem pesquisa que abordou a representação do direito à saúde dos usuários de um serviço específico do município de Valença, RJ. Dimenstein et al. discutem como familiares de portadores de transtornos mentais têm experienciado as mudanças nas políticas da área, com base em pesquisa empírica realizada em Natal, RN. Soratto, Witt e Faria relatam um estudo de pesquisa-ação sobre participação popular e controle social na região sul de Santa Catarina. Encerrando este bloco e o tema, Guizardi e Cavalcanti discutem o conceito de cogestão formulado por Gastão W. Campos numa proposta de revisão dos modos de gestão do SUS.

Abrindo a seção de temas livres, o ensaio de Arreguy é uma interpretação das teorias neurofisiológicas das emoções que as relacionam ao comportamento violento, a fim de apresentar uma crítica ao seu uso indiscriminado. Após este, Rocha et al. analisam o conhecimento e percepção de um grupo de mulheres sobre o aleitamento materno. Segue-se o texto de Carvalho, Assunção e Bocchi, que descrevem sua revisão de literatura sobre o atendimento ao idoso no âmbito da ESF.

Cavaliere, Souza e Barbosa apresentam dados de pesquisa com mulheres em programa terapêutico não-medicamentoso paras fibromialgia, enfocados nas suas representações sociais sobre este processo. Nunes, Castellanos e Barros trazem importante reflexão sobre a importância da narrativa tanto como instrumento de pesquisa como recurso indispensável na produção do cuidado aos sujeitos. Sabino e Luz discutem a função do ambulatório na dinâmica das relações de 
poder e construção de identidade da profissão de terapeuta da medicina ocidental contemporânea, com base em entrevistas com médicos e observação direta em duas unidades assistenciais da cidade do Rio de Janeiro, RJ.

Pellon e Vargas propõem uma reflexão sobre a política de saúde indígena em nosso país, a partir de pesquisa realizada no município de Aracruz, ES. A saúde indígena é também tema do trabalho de Vargas et al., que buscaram avaliar as estratégias de articulação locorregionais dos diferentes níveis de atenção à saúde voltados para os bororo no Pólo-Base Rondonópolis, MT.

Encerrando a edição, Moimaz et al. apresentam os resultados de inquéritos sobre satisfação dos usuários dos serviços de saúde de cinco municípios de São Paulo.

Este número encerra o vigésimo volume de Physis. Em momentos anteriores, celebramos a história de nossa revista, do IMS-UERJ, responsável por esta publicação, e do próprio SUS. Para não soarmos repetitivos, não vamos retomar todos os marcos dessa jornada memorável, mas queremos de todo modo agradecer a todos - e são muitos - aqueles que contribuem para a consolidação de Physis entre as revistas relevantes da Saúde Coletiva brasileira. A melhor forma que encontramos de fazê-lo é celebrar os colaboradores que, com seu esforço anônimo, constituem a espinha dorsal do periodismo científico: os pareceristas. Ao final desta edição, temos a lista dos nossos contribuidores silenciosos, a primeira e mais importante linha de garantia de qualidade de nossa revista, os pareceristas que avaliaram os artigos publicados neste ano. A todos vocês, nosso agradecimento, e por meio de vocês, nosso agradecimento aos autores, leitores, conselho editorial e tantos outros que fazem de Physis o que ela é.

Desejamos a todos boas festas e um 2011 ainda melhor. 